\title{
MITOLOGIA E IDENTIDADE ARTÍSTICA: UM ESTUDO DA PRESENCCA DE MITEMAS HERÓICOS NO DISCURSO DE PAULO PASTA E DA CRÍTICA CONTEMPORÂNEA. ${ }^{1}$
}

\author{
Antonio Carlos Vargas Sant'Anna², Renata Amabile Patrão ${ }^{3}$
}

Palavras-chave: Mitologia artística - mitologia heróica - Paulo Pasta

Resumo: O presente artigo fundamenta-se na Hermenêutica Simbólica do Círculo de Eranos para realizar a análise e reflexão sobre a negação ou afirmação da mitologia heróica no discurso do pintor Paulo Pasta e críticos, verificando-se como o mito do herói serve de mediador na construção da identidade artística e na aceitação e interpretação da obra de arte.

Ao longo do processo de secularização da arte, a obra sofreu uma perda de potência simbólica, decorrente do não reconhecimento de sua natureza divina. Como estratégia compensatória, verificou-se um deslocamento das características míticas da obra, projetadas agora sobre o autor, configurando-se o mito do artista. Deduz-se, portanto, que o mito exerça um papel determinante na aceitação ou rejeição de comportamentos artísticos, uma vez que media a construção e interpretação da obra de arte.

A pesquisa foi fundamentada epistemologicamente na Hermenêutica Simbólica e no entendimento do conceito de símbolo e mito utilizado por pesquisadores vinculados ao Círculo de Eranos, como o antropólogo francês Gilbert Durand.

Durand (1988, p. 15) define o símbolo como "a epifania de um mistério", uma vez que este remete ao não-sensível em todas as suas formas - inconsciente, metafísica, sobrenatural e supra-real. Em função de sua inadequação fundamental uma vez que nunca atinge um objeto - o símbolo opera através da redundância, entendida como repetição aperfeiçoadora. Por meio de aproximações acumuladas, a

\footnotetext{
${ }^{1}$ Projeto de Pesquisa Mitologia e identidade artística: um estudo da presença de mitemas heróicos no discurso de artistas e críticos - CEART/UDESC.

${ }^{2}$ Orientador, Professor do Departamento de Artes Plásticas - Centro de Artes - Av. Madre Benvenuta, 1907 - CEP 88035-001 - Florianópolis - SC.

${ }^{3}$ Acadêmica do curso de Bacharelado em Artes Plásticas - CEART/UDESC, bolsista de iniciação científica do PIBIC/CNPq.
}

DAPesquisa, Florianópolis, v.2, n.4, p. 325-329, 2007. 
redundância é significativa do mito. Daí a formulação metodológica centrada na compreensão do relato mítico inerente à significação de todo discurso como possibilidade de aproximação da obra, considerando-se que esta também é símbolo. Nesta concepção de mundo, o conhecimento do homem começa pelo conhecimento dos deuses e da mitologia como relato de uma história sagrada, atemporal e exemplar, sobre a qual se modela, por repetição, todo acontecimento histórico. Através do conhecimento dos deuses o homem pode chegar ao autoconhecimento, em virtude das similitudes existentes entre o humano e o divino.

Segundo Durand (1997), o mito é um sistema dinâmico de símbolos que, sob o impulso de um esquema, tende a compor-se em narrativa. A partir desta concepção, Luis Garagalza (1990) afirma que toda obra deve ser compreendida como um universo que ordena e articula valores e, por serem esses valores de procedência numinosa ${ }^{4}$, a compreensão exige uma referência explícita aos grandes mitos, nos quais se implica a numinosidade última. Os deuses intervêm no mito como potências antagonistas personificadas, protagonizando uma história exterior ao tempo, podendo por isso atualizar-se em cada presente. Integrados em mitemas - menor unidade do discurso miticamente significativa, segundo definição antropológica -, os símbolos não esgotam sua significação na seqüência linear da narrativa, agindo pela redundância. Daí a necessidade de uma análise sincrônica dos mitemas inerentes ao relato mítico.

Dentre as narrativas encontradas nas diferentes culturas humanas, os mitos heróicos configuram como as de maior impacto. Em uma introdução ao mito dos heróis, Junito de Souza Brandão (1997) apresenta a trajetória heróica de forma didática e esquematizada, fornecendo uma síntese de suas atividades e características fundamentais. Este ser singular é acompanhado do nascimento à morte, passando pelas importantes etapas de iniciação e aprendizado. Um dos símbolos mais importantes existentes, a vivência heróica emociona porque, apesar de possuir uma origem divina e realizar feitos singulares, o herói também sofre e possui uma existência finita. Porém, ao empreender sua jornada, ele transcende sua condição humana e reverte suas conquistas à comunidade, justificando sua existência.

\footnotetext{
${ }^{\overline{4}}$ Rudolf Otto (1992) conceitua o elemento especial compreendido no sagrado, denominado numinoso. Destituído de toda ordem ética e moral, este elemento possui uma qualidade singular que escapa a toda racionalidade, constituindo uma arrêton (indizível), algo de inefável.
}

DAPesquisa, Florianópolis, v.2, n.4, p. 325-329, 2007. 
O método de pesquisa foi adotado a partir da hipótese de que, tanto a definição do resultado da ação artística como Arte, quanto a definição do objeto simbólico, possuem a mesma raiz. Confrontando-se os mitemas identificados no discurso de artistas e críticos com as categorias de heroísmo, foi possível comprovar o redobramento do mito do herói no mito do artista, uma vez que "o mito do artista existe e é necessário porque o artista, [...] enquanto personagem heróico, é símbolo." (VARGAS, 2004/2005, grifo do autor).

Em um primeiro momento, realizou-se a análise de discurso do pintor paulista Paulo Pasta e de textos de críticos contemporâneos, efetuando-se a decomposição dos mitemas que constituem a sincronicidade mítica do relato. A escolha de Pasta foi determinada pela sua intensa atividade e comprovada inserção no circuito artístico oficial. Foram utilizadas entrevistas e declarações coletadas em sites, livros, vídeo e DVD dedicados ao artista.

Posteriormente, realizou-se a confrontação dos motivos redundantes encontrados nos relatos com as principais categorias de heroísmo, tomando como referência os estudos sobre o mito do artista na cultura ocidental. Considerando-se que o mito atua através da estratégia de "sobreposição" de conteúdos, as categorias heróicas foram substituídas por um conjunto de características e imagens míticas historicamente associadas ao artista que, conseqüentemente, possuem uma representação simbólica.

Como resultado, verificamos que a decomposição dos relatos coletados e a posterior confrontação com as principais categorias de heroísmo confirmaram a presença de mitemas heróicos no discurso de Paulo Pasta e da crítica. Os relatos recorrem aos mitemas de nascimento ao fazer referência a fatos importantes ocorridos na juventude de Pasta - convívio do artista ainda menino com a obra de familiares, a promessa prematura de ser pintor e o abandono relacionado com o período anterior ao aprendizado e à realização da ação heróica. Seguem-se os mitemas relacionados ao chamado, indicando um momento de revelação, onde o pintor toma conhecimento de sua verdadeira natureza.

Ao aceitar o chamado, o pintor inicia a jornada heróica-artística propriamente dita, iniciando o aprendizado. Os mitemas que valorizam a destreza do herói no domínio das armas passam a enriquecer a narrativa através de relatos que indicam o domínio dos recursos plásticos utilizados por Pasta. 
Assim como o mitema de domínio técnico, os mitemas de superação do mestre também são freqüentes, simbolizados na mediação da obra de Pasta com Volpi e Morandi. O acréscimo de conhecimento, obtido na medida em que o artista recorre aos ensinamentos dos mestres e supera-os, é lido como uma contribuição para a melhoria da coletividade.

A realização da ação heróica e consqüente melhoria coletiva é resultado de um esforço árduo e muito sofrimento. Esforço e sofrimento transformam-se em luta, na medida em que Pasta revela sua obstinação em insistir com a pintura, apesar desta já ter sua "morte" decretada. A obstinação pode caracterizar um comportamento heróico-artístico: ao aceitar o desafio da jornada, o herói abdica de seus caprichos individuais e dedica-se a uma causa maior, o que justifica a obsessão no exercício das práticas.

A destreza de Pasta passa a realizar-se pelo domínio das armas interiores (espirituais), associada a imagens relacionadas com as metamorfoses, com as transmutações alquímicas, com a idéia de experimentação e transformação. O poder de transformar o banal em singular é reconhecido e valorizado, uma vez que a verdadeira façanha heróica consiste na reprodução em linguagem mundana dos ensinamento do reino sagrado. $O$ artista cumpre o objetivo final da trajetória heróica quando consegue transfigurar a sabedoria conquistada e apresentá-la para a humanidade, auxiliando àqueles que continuam presos ao seu tempo e espaço a transformar suas vidas.

Assim como o herói, Pasta simbolicamente empreendeu uma árdua jornada, superou seu egoísmo humano e teve o direito de conhecer os segredos dos deuses. Ele está pronto para retornar e compartilhar o que aprendeu, garantindo à comunidade sua renovação e transformação.

A verificação da presença de mitemas heróicos no discurso de Pasta e da crítica contemporânea comprova a influência da mitologia nos processos de construção da identidade artística. O mito continua vivo e atuante, servindo de base sobre a qual se estrutura a imagem do artista. A mitologia ensina que a obra de arte é símbolo e, como tal, requer revelação. O artista, enquanto símbolo, possibilita a manifestação desse mistério ao transfigurar o comum em singular. O mundo, agora transformado, pode testemunhar a epifania que denominamos Arte. 
BRANDÃO, J. de S. Mitologia grega. 7. ed. Petrópolis: Vozes, 1997. v. 3.

DURAND, G. A imaginação simbólica. São Paulo: Cultrix, 1988.

As estruturas antropológicas do imaginário: introdução à arqueologia geral. São Paulo: Martins Fontes, 1997.

GARAGALZA, L. La interpretación de los símbolos: hermenéutica y lenguaje en la filosofía actual. Barcelona: Anthropos, 1990.

OTTO, R. O sagrado. Rio de Janeiro: Ed 70, 1992.

VARGAS, A. Do valor da prática à prática de valor. PONTO DE VISTA,

Florianópolis, n. 6/7, p. 11-25, 2004/2005. 